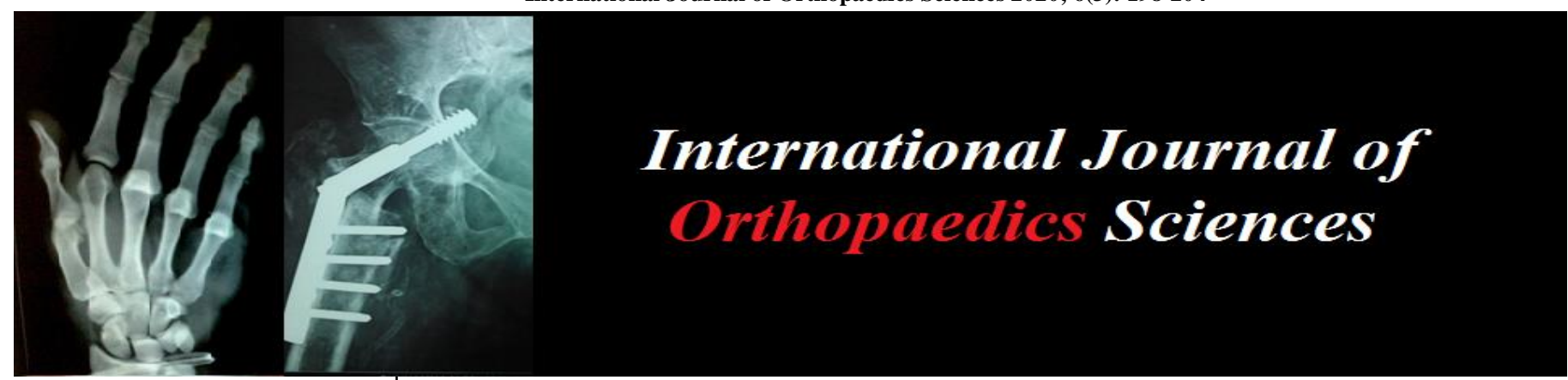

E-ISSN: 2395-1958

P-ISSN: 2706-6630

IJOS 2020; 6(3): 198-204

(C) $2020 \mathrm{IJOS}$

www.orthopaper.com

Received: 05-05-2020

Accepted: 07-06-2020

Dr. Abhijeet Shinde

DNB Orthopaedics, Senior

Resident, GMC Bhavnagar,

Gujarat, India

Dr. Akshay Patel

MS Orthopaedics, GMC

Bhavnagar, Gujarat, India

Dr. Maulik Pate

DNB Orthopaedics, GMC

Bhavnagar, Gujarat, India

Dr. Neeraj Gupta

MS Orthopaedics, Senior

Medical Officer, GMSH

Chandigarh, India
Corresponding Author: Dr. Abhijeet Shinde DNB Orthopaedics, Senior Resident, GMC Bhavnagar, Gujarat, India

\section{A comparative study of passive stretching vs corticosteroid injection vs therapeutic ultrasound in plantar fasciitis}

\author{
Dr. Abhijeet Shinde, Dr. Akshay Patel, Dr. Maulik Patel and Dr. Neeraj \\ Gupta
}

DOI: https://doi.org/10.22271/ortho.2020.v6.i3d.2199

\section{Abstract}

Background and Objective: This study compares passive stretching, corticosteroid injection and therapeutic ultrasound in plantar fasciitis.

Materials and Methods: A total of 75 patients (age range, 18-60 years; 38 females) with PF were randomly assigned to receive either passive stretching $(n=25)$ or corticosteroid injection $(n=25)$ or therapeutic ultrasound $(n=25)$. Passive stretching included both plantar fascia specific stretching exercise and Achilles tendon stretching exercise each applied in 10 sets of 10 -second stretch and a 10 -second rest 3 times a day for 6 months and supervised two times per week for 4 weeks to ensure that patients were doing the passive stretching exercise properly as they were advised. The corticosteroid injection group received a single palpation guided mixture of $40 \mathrm{mg}$ of methylprednisolone and $2 \mathrm{ml}$ of $2 \%$ lignocaine injection at baseline. Therapeutic ultrasound group received continuous mode, base frequency of $1 \mathrm{MHz}$, power $2 \mathrm{w} / \mathrm{cm} 2$, applied during three minutes each on calcaneus medial tuberosity and on the $2 \mathrm{~cm}$ distal to tuberosity three times a week, for four weeks duration (total 12 sessions). Also the patients in all the 3 groups were advised to use silicon heel pads as a common modality of treatment. The patients' functional outcome was assessed using the Foot and Ankle Ability Measure (FAAM), and relief of pain was evaluated using the Visual Analog Scale (VAS). Outcomes of interest were recorded before the treatment and at 1 month, 3 month \& 6 month follow-ups.

Results: Age, sex and body mass index did not significantly impact pain relief or functional outcome $(P$ $>0.05$ ). Out of 75 planned subjects only 68 patients could be followed up. Planned pair-wise comparisons demonstrated significant improvements in pain relief and functional outcomes in terms of both VAS $(P<0.05)$ and FAAM $(P<0.05)$ in all the three groups at the 1 month and 3 months follow ups compared to baseline. At 6 months, the effects were significant only in passive stretching and corticosteroid injection groups ( $\mathrm{p}=0.0001$ for both VAS and FAAM) but effects of therapeutic ultrasound were non-significant $(\mathrm{p}-0.107)$. Between-group differences favored the corticosteroid injection group over passive stretching group both at the 1 month and 3 months (VAS $P=0.0001$, FAAM $P=0.001$ ) and also favored over therapeutic ultrasound at all the three follow ups (VAS $P=0.001$, FAAM $P=0.001$ ). At 6 months, the effects of passive stretching were better than corticosteroid injection (VAS $P=0.002$, FAAM $P=0.001)$

Conclusion: From our study, it is concluded that in patients with plantar fasciitis for the short term (up to 3 months) relief of pain and functional improvement, all the three treatment modalities were effective in the order: corticosteroid injection >passive stretching >therapeutic ultrasound. But for the long term improvements (6 months), passive stretching was more effective than corticosteroid injection and therapeutic ultrasound was not effective. Hence passive stretching exercise is recommended as a primary line of treatment as it is a non-invasive modality, avoids complications associated with steroid injection and has long lasting effects.

Keywords: Plantar fascia, plantar fasciitis, passive stretching, therapeutic ultrasound, local steroid injection

\section{Introduction}

Plantar fasciitis has been reported as the most common cause of pain in the inferior heel, is estimated account for 11 to $15 \%$ of all foot symptoms requiring professional care among adults ${ }^{[1]}$. It has been estimated that plantar fasciitis affects as much as $10 \%$ of the population 
over the course of a lifetime ${ }^{[2]}$. There is excessive stress to the plantar fascia that supports the arches of the foot or biomechanical faults that cause abnormal pronation ${ }^{[3]}$. Although thought of as an inflammatory process, plantar fasciitis is a disorder of degenerative changes in the fascia, and may be more accurately termed plantar fasciosis ${ }^{[4]}$. The classical presentation of plantar fasciitis includes a gradual, insidious onset of infero-medial heel pain at the insertion of the plantar fascia. Pain and stiffness are worse with first step after getting up in the morning or walking after prolonged rest [5]. The patient usually has tenderness around the medial calcaneal tuberosity at the plantar aponeurosis ${ }^{[6]}$

The etiology of this condition is multifactorial, and the condition can occur traumatically; however, most cases are from overuse stresses. Excess weight, age related degenerative changes and occupations requiring prolonged standing or ambulation or sports that involve running, long distance walking, dances, tennis players, basketball players contribute to the risk of plantar fasciitis ${ }^{[7-8]}$. However, various non-functional etiologies also exist, which constitute the remaining $10 \%$ like sero-negative arthropathies ${ }^{[9]}$.

Medical management for the condition includes nonsteroidal anti-inflammatory drugs (NSAIDs) or local cortisone injections. Surgical management includes resection of the calcaneal spur, resection of part of the plantar fascia near its origin and excision of the medial inferior tubercle of the calcaneus. There are many other therapies that have been suggested for the treatment of plantar fasciitis, they are acupuncture, electron generating devices, insoles with magnetic foil, extracorporeal shock wave therapy (ESWT) ${ }^{[10] .}$ There are various physiotherapy treatment protocols which have been advocated in the past such as rest, orthosis-night splint, silicon heel cups, stretching, myofascial release, positional release therapy and taping is one among them. Electrotherapy modalities in the form of ultrasound, phonophoresis, laser, microwave diathermy, iontophoresis, cryo-therapy, contrast bath therapy have been tried ${ }^{[11]}$.

Stretching is the deliberate act of lengthening of muscles, in order to increase muscle flexibility and/or joint range of motion. Stretching appears to be the easiest, most useful technique to alleviate the symptoms associated with plantar heel pain. Stretching of the Achilles tendon and plantar fascia, performed 3-5 times daily, has been shown to be effective in decreasing the pain at the plantar fascia ${ }^{[12]}$.

Localised steroid injections into the plantar fascia have been shown to provide effective short-term relief of plantar fascia pain for up to three months ${ }^{[13]}$. There is, however, increased risk of plantar fat pad atrophy and plantar fascia rupture with repeated corticosteroid injections ${ }^{[14]}$, and thus, repeated injections should be avoided if possible ${ }^{[15]}$.

Therapeutic Ultrasound is a method of applying deep heat to connective tissue ${ }^{[14]}$ which plays an important role in relieving plantar heel pain by both thermal and mechanical effect on target tissue resulting in increased local metabolism, circulation and extensibility of connective tissue and tissue regeneration. To obtain increase in the viscoelastic properties of collagen, an elevation in tissue temperature of greater than $3^{\circ}$ to $4^{\circ} \mathrm{C}$ is indicated ${ }^{[16]}$.

Passive stretching exercises, local corticosteroid injection and therapeutic ultrasound are commonly used treatment modalities in plantar fasciitis. On exploring literature on reputed websites, it was found that not much work has been done on comparative analysis of these modalities of treatment of heel pain. The available reports are usually conflicting as to the most appropriate line of treatment. In view of the above, more focused study is required to evaluate the various modes of treatment of plantar fasciitis. The present study is a step in this direction.

\section{Material and Methods}

The present study was conducted in the Department of Orthopaedics, Govt. Multi-specialty Hospital, Sector 16, Chandigarh during the study period of 2 years from October 2015 to September 2017 after the approval by Ethics committee.

\section{Study Design}

The study was prospective, single blinded, observational, time bound, hospital based, randomized study. In this study, 75 patients of plantar fasciitis of either sex satisfying the inclusion criteria were enrolled after taking consent. Patients were randomly divided into three groups of 25 patients each. Group A was managed with passive stretching exercise daily for the period of 6 months, Group B with single palpation guided corticosteroid injection and group $\mathrm{C}$ with therapeutic ultrasound thrice a weekly for 4 weeks. Patients were followed up monthly over a period of 6 months and pretreatment and post-treatment pain level was assessed by Visual Analog Scale (VAS) and Functional outcome was assessed by Foot and Ankle Ability Measure (FAAM) Scale at 1 month, 3 months and 6 months. Also all the patients were trained to do VAS scoring on their own and asked to fill daily VAS score. Also in between the scheduled visits patients contacted us telephonically or through messages whenever they had increase in pain or any other query and they were examined whenever it was found necessary. The patients were also counseled that they should avoid taking pain killers in mild to moderate pain so as to avoid masking of the beneficial effects of treatment modalities. Also the patients were advised to avoid strenuous activities like running, jumping, jogging etc. during the study period so as not to aggravate the pain. The comparative analysis of three regimens was done at the end of the study.

\section{Participants}

Sample size was estimated based on assumption that the incidence rate of plantar fasciitis is $10 \%$. To estimate this proportion with a $95 \%$ confidence interval of proportion \& error of $7.1 \%$ the sample size required was calculated as 68 subjects by using the formula $\mathrm{n} 0=(\mathrm{z})^{2}(\mathrm{p})(\mathrm{q}) /(\mathrm{d})^{2}$. For possible dropouts, it was decided to include $10 \%$ extra subjects so finally it was decided to include 75 subjects in the study.

The inclusion criteria required the participants of both genders between the age group 18-60 years to have unilateral maximal pain located at the infero-medial aspect of the plantar surface of the calcaneus ${ }^{[5]}$, Pain that is worst on the first few steps in the morning [5], tenderness around the medial calcaneal tuberosity, heel pain on weight bearing activity for a minimum of four weeks and a maximum of twelve months.

All patients of having History of pathologies around ankle/foot including tendonitis, bursitis, or calcaneus fracture, Any infective pathology of hind foot like cellulitis, chronic osteomyelitis, History of auto immune or systemic inflammatory disorders including rheumatoid arthritis, ankylosing spondylitis, etc, Subjects with fixed deformities of foot and ankle, fixed deformities of foot and ankle are excluded. Plain radiograph of foot AP and oblique view and ankle AP and lateral view and laboratory investigations like random blood sugar, complete blood count, ESR and CRP were done to rule out other causes of heel pain. 
Table 1: Patient Demographics

\begin{tabular}{|c|c|c|c|c|}
\hline & PS & SI & TU & P-Value \\
\hline AGE & 36.178 .53 & 39.739 .98 & 39.577 .91 & 0.715 \\
\hline BMI & 21.7 & 39.7 & 27.3 & 0.417 \\
\hline Duration of symptoms & 12.17 & 10.78 & 11.41 & 0.816 \\
\hline
\end{tabular}

\section{Interventions}

\section{- Passive Stretching Exercises Procedure}

Patients were advised both plantar fascia specific stretching exercise and Achilles tendon stretching exercise.

\section{Plantar Fascia Stretching Protocol ${ }^{[17]}$.}

The patient was instructed to first cross the affected leg over the contralateral leg while seated. The patient then applied force distal to the metatarsophalangeal joints on the affected side, pulling the toes upward toward the shin until a stretch was felt in the sole of the foot. Tension in the plantar fascia was palpated with the contralateral hand while performing the stretch. This exercise was advised while keeping the ankle in dorsiflexion as it produces more tension in plantar fascia. The patients were advised 10 sets of 10 -second stretch and a 10second rest of plantar fascia specific stretching exercise performed thrice a day.

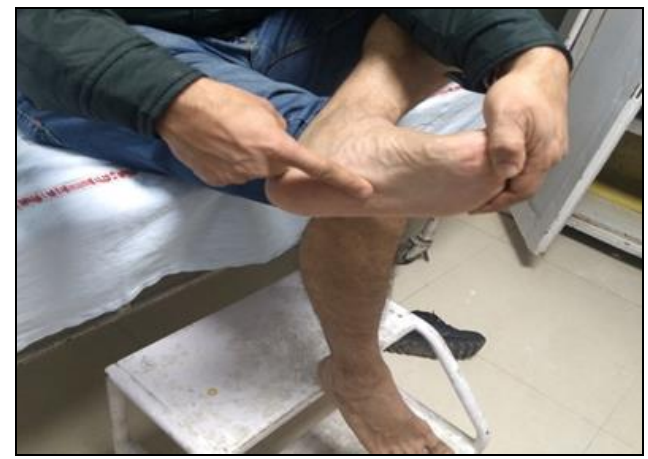

Fig 1: Plantar fascia stretching

\section{Achilles Tendon-Stretching Program ${ }^{[17]}$.}

Patients were taught to perform this exercise while standing and leaning into the wall with the affected leg placed behind the contralateral leg. They were also instructed to "toe in" or point the toes of the affected foot toward the heel of the front foot. Patients were told to bend the front knee while keeping the back knee straight and the heel firmly on the ground. The patients were advised 10 sets of 10 -second stretch and a 10second rest of Achilles tendon stretching exercise performed thrice a day.

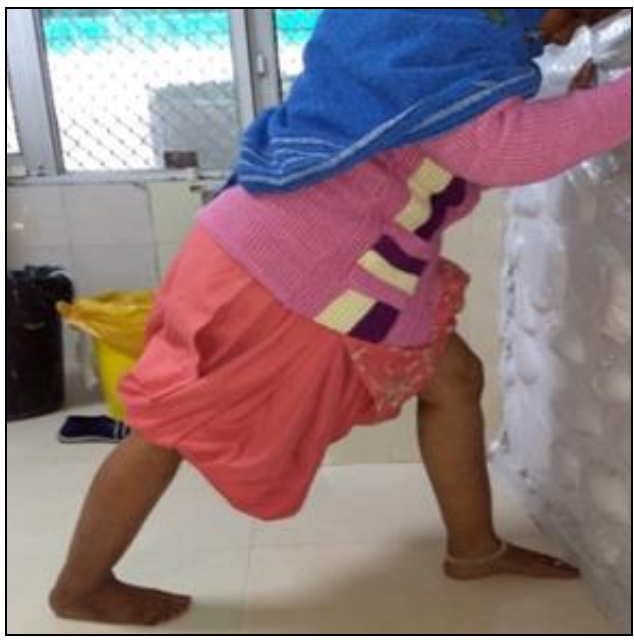

Fig 2: Achilles tendon stretching
This stretching exercises protocol was advised daily for 6 months duration and was supervised two times per week for the first 4 weeks to ensure that patients were doing the passive stretching exercise properly as they were advised.

Patients were advised to do first stretch before the first step taken in the morning daily.

\section{- Local Corticosteroid Injection Procedure}

Under aseptic precautions with 20 gauge, 1.5 -inch $(3.8-\mathrm{cm})$ needle attached to $5 \mathrm{ml}$ syringe containing a mixture of $2 \mathrm{ml}$ of $2 \%$ lignocaine and $1 \mathrm{~mL}(40 \mathrm{mg})$ of methylprednisolone was injected in the most anterior aspect of the medial plantar calcaneal tuberosity is palpated and tenderness at this is confirmed. ${ }^{18}$ The needle is inserted by medial approach and advanced until it reaches the point just anterior to the most distal aspect of the plantar medial calcaneal tuberosity. Injecting within the superficial layers of the subcutaneous tissue was avoided, because corticosteroid injection into the superficial fat pad can cause fat necrosis and atrophy, which reduce the shock-absorbing capacity of the plantar heel. Then wound is dressed with an occlusive dressing. Post injection patient is advised restricted activity for 2 days.

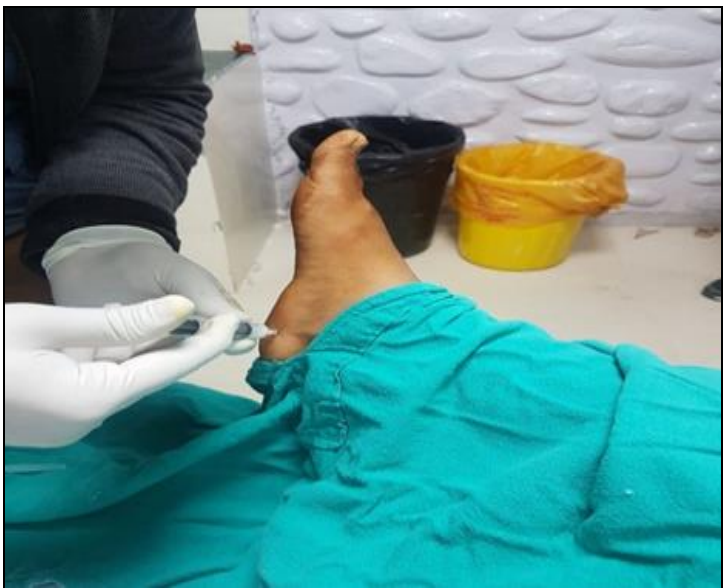

Fig 3: Corticosteroid injection site

All the patients were informed that there may be soreness and pain at the injection site for the first 48 hours for which they were told to apply ice packs and were advised to watch for signs of infections like redness, increased swelling or warmth at the injection site that lasts more than 48 hours postinjection and contact us.

All the patients were watched for general risks involved with the use of corticosteroids like skin atrophy, skin hypopigmentation, soft-tissue atrophy, infection, bleeding, and failure to work or steroid flare up (increased pain for up to several days, may occur in up to $2 \%$ of individuals who use corticosteroids) ${ }^{[19]}$ at the follow up visits.

\section{- Therapeutic Ultrasound treatment procedure ${ }^{[20]}$}

Therapeutic Ultrasound is applied in the following steps: In prone position, medial calcaneal tuberosity is palpated and marked and some amount of ultrasound gel is applied. Continuous mode, base frequency of $1 \mathrm{MHz}$, power $2 \mathrm{w} / \mathrm{cm} 2$, applied during three minutes each on calcaneus medial tuberosity and on the $2 \mathrm{~cm}$ distal to tuberosity. However, temporary pain at site of ultrasound application made the steady application impossible. Thus, the equipments headstock position was slightly changed for a few seconds, until pain ceased. The patients were given therapeutic ultrasound three times a week, for the duration of four weeks (total 12 sessions). 


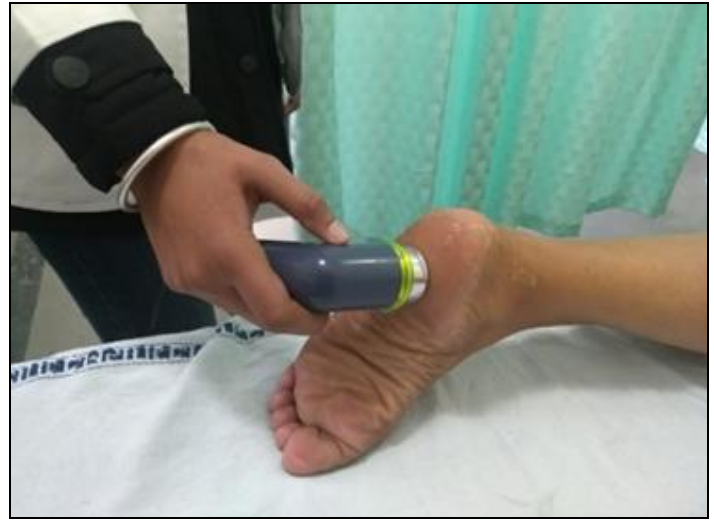

Fig 4: Therapeutic ultrasound

\section{Follow-up}

Patients were reviewed regularly 1 month, 3 months and 6 months postoperatively. Also in between the scheduled visits patients contacted us via telephonic conversation or messages whenever they complained of increase in pain or had any other query and they were examined whenever it was found necessary. They were assessed clinically at each follow up to evaluate pain relief by visual analogue scale and functional outcome by foot and ankle ability measure and to watch for any of the following complications.

\section{Outcome Measures}

1. Visual analogue Scale ${ }^{[21]}$.

A horizontal visual analogue scale was used. A $10 \mathrm{~cm}$ line was drawn on a paper and participants were asked to mark a point on the line that best defined the present pain level, where 0 indicated no pain and 10 indicated unbearable pain. Visual analogue scale was taken pre-interventionally and at each follow up. The patients were advised to mark VAS score for pain during function.

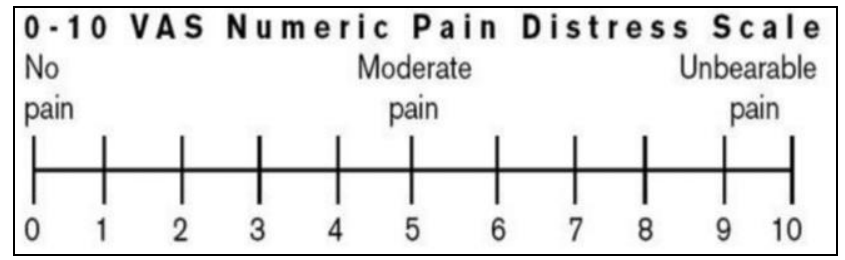

Fig 5: VAS

\section{Foot and Ankle Ability Measure (FAAM) ${ }^{[22]}$} Activities of Daily Living Subscale

There are total 21 questions in this scale. The response to each item on the ADL subscale is scored from 4 to 0 , with 4 being "no difficulty" and 0 being "unable to do". N/A responses are not counted. The score on each of the items are added together to get the item score total. The total number of items with a response is multiplied by 4 to get the highest potential score. The item score total is divided by the highest potential score. This value is then multiplied by 100 to get a percentage. A higher score represents a higher level of physical function. If the activity in question is limited by something other than your foot or ankle mark "Not Applicable" (N/A).

\section{Results}

The results of our study demonstrated that all the three groups achieved significant improvements compared to pre-treatment status at 1 month and 3 month follow-up both in terms of VAS and FAAM $(p<0.05)$. At 6 months follow up passive stretching and steroid injection groups achieved significant improvements $(p<0.05)$ but therapeutic ultrasound group didn't achieve a significant improvement shown by VAS (p$0.107)$ and FAAM (p-0.162)

The improvements progressed only in the stretching group and were maintained in steroid injection group at 3 months. The result of therapeutic ultrasound decreased at 3 months compared to 1 month follow up but still it was significant when compared to pre-treatment level (VAS P-0.0001, FAAM P-0.0001).

The results also suggest that the treatment approach in the steroid injection group provided greater clinical benefits in terms of function (FAAM score) and pain (VAS score) than those experienced by the passive stretching group at the follow-up periods of 1 month (VAS P-0.0001, FAAM P0.0001 ) and 3 months (VAS P-0.0001, FAAM P-0.0001). However, the superiority of steroid injection was not maintained at the 6 month follow-up, and effects of passive stretching were better than steroid injection ( $p$-value 0.002). The results of therapeutic ultrasound decreased consistently from 3 months to 6 months follow up and it was not significant at 6 month compared to pre-treatment level shown by VAS (p-0.107) and FAAM (p-0.162).

Table 2: Intra-group Comparison of treatment modalities with baseline

\begin{tabular}{|c|c|c|c|c|c|c|c|c|}
\hline \multirow{4}{*}{ VAS } & & $\begin{array}{c}\text { BASELINE MEAN } \\
+/- \text { SD }\end{array}$ & $\begin{array}{c}1 \text { MONTH } \\
\text { MEAN +/- SD }\end{array}$ & P VALUE & $\begin{array}{c}3 \text { MONTH } \\
\text { MEAN +/- SD }\end{array}$ & P VALUE & $\begin{array}{c}6 \text { MONTH } \\
\text { MEAN +/- SD }\end{array}$ & P VALUE \\
\hline & $P S$ & $7.52+/-0.99$ & $5.35+/-0.98$ & 0.0001 & $4.83+/-1.27$ & 0.0001 & $2.74+/-1.25$ & 0.0001 \\
\hline & $S I$ & $7.65+/-1.34$ & $2.26+/-0.92$ & 0.0001 & $2.57+/-1.47$ & 0.0001 & $4.13+/-1.66$ & 0.0001 \\
\hline & $T U$ & $7.23+/-1.27$ & $5.27+/-1.28$ & 0.0001 & $5.73+/-1.24$ & 0.001 & $6.95+/-1.21$ & 0.107 \\
\hline \multirow{4}{*}{ FAAM } & & $\begin{array}{c}\text { BASELINE MEAN } \\
+/- \text { SD }\end{array}$ & $\begin{array}{c}1 \text { MONTH } \\
\text { MEAN +/- SD }\end{array}$ & P VALUE & $\begin{array}{c}3 \text { MONTH } \\
\text { MEAN +/- SD }\end{array}$ & P VALUE & $\begin{array}{c}6 \text { MONTH } \\
\text { MEAN +/- SD }\end{array}$ & P VALUE \\
\hline & $P S$ & $47+/-5.75$ & $52.28+/-7.37$ & 0.0001 & $62.3+/-9.17$ & 0.0001 & $73.18+/-10.13$ & 0.0001 \\
\hline & $S I$ & $46.4 .+/-4.63$ & $69.32+/-6.11$ & 0.0001 & $65.98+/-5.25$ & 0.0001 & $60.7 .+/-7.64$ & 0.0001 \\
\hline & $T U$ & $49.47+/-7.83$ & $57.69+/-8.89$ & 0.0001 & $53.98+/-8.67$ & 0.0001 & $51.34+/-9.10$ & 0.162 \\
\hline
\end{tabular}

Table 2: Inter-group VAS Comparisons

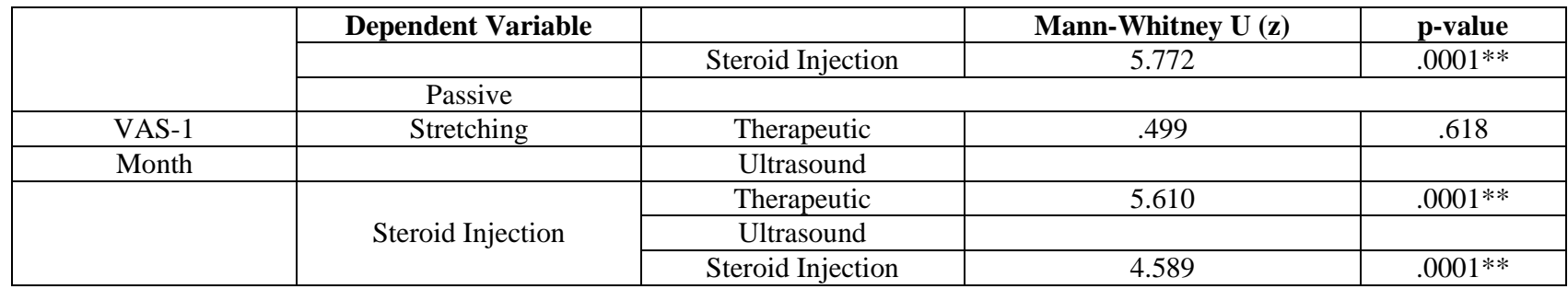




\begin{tabular}{|c|c|c|c|c|}
\hline & Passive & & & \\
\hline VAS-3 & Stretching & Therapeutic & 2.444 & $.015^{*}$ \\
\hline Month & & Ultrasound & & \\
\hline \multirow[t]{4}{*}{ thesing } & \multirow{3}{*}{ Steroid Injection } & Therapeutic & 5.063 & $.0001 * *$ \\
\hline & & Ultrasound & & \\
\hline & & Steroid Injection & 3.102 & $.002 * *$ \\
\hline & \multirow{3}{*}{$\begin{array}{c}\text { Passive } \\
\text { Stretching }\end{array}$} & & & \\
\hline VAS-6 & & Therapeutic & 5.643 & $.0001 * *$ \\
\hline \multirow[t]{3}{*}{ Month } & & Ultrasound & & \\
\hline & \multirow{2}{*}{ Steroid Injection } & Therapeutic & 4.854 & $.0001 * *$ \\
\hline & & Ultrasound & & \\
\hline
\end{tabular}

\section{Discussion}

Plantar fasciitis is the most common cause of heel pain for which professional care is sought ${ }^{[1]}$. Passive stretching exercises, corticosteroid injection and therapeutic ultrasound are commonly used treatment modalities in practice. But there to our knowledge is no published research which compares all of these three treatment modalities in a single study and there are very few studies which compare stretching exercises with corticosteroid injection. Hence, the present study was an attempt to evaluate the comparative efficacy of passive stretching exercises, corticosteroid injection and therapeutic ultrasound

The results of our study demonstrated that all the three groups achieved significant improvements compared to pre-treatment status at 1 month and 3 month follow-up both in terms of VAS and FAAM. At 6 months follow up passive stretching and steroid injection groups achieved significant improvements but therapeutic ultrasound group didn't achieve a significant improvement.

When compared to each other, the improvements achieved at 1 month were in order of steroid injection > passive stretching $>$ therapeutic ultrasound. The improvements progressed only in the stretching group and were maintained in steroid injection group at 3 months. The result of therapeutic ultrasound decreased at 3 months compared to 1 month follow up but still it was significant when compared to pre-treatment level.

The results also suggest that the treatment approach in the steroid injection group provided greater clinical benefits in terms of function (FAAM score) and pain (VAS score) than those experienced by the passive stretching group at the follow-up periods of 1 month and 3 months. However, the superiority of steroid injection was not maintained at the 6 month follow-up, and effects of passive stretching were better than steroid injection (p-value 0.002). The results of therapeutic ultrasound decreased consistently from 3 months to 6 months follow up and it was not significant at 6 month compared to pre-treatment level.

From this study, it can be recommended that patients can be managed conservatively with non-invasive methods like passive stretching exercises and therapeutic ultrasound up to3 months as the effects of these modalities in our study were statistically significant when compared to pre-treatment level. Local steroid injection though more effective than passive stretching exercise and therapeutic ultrasound up to 3 months should be reserved for non- responsive or resistant cases having severe pain due to risk of complications like spontaneous plantar fascia rupture, flattening of longitudinal arch of foot, heel fat pad atrophy and injection site infection though not observed in present study. Steroid injection should be avoided in athelets as they have greater risk of spontaneous rupture of plantar fascia. Also continued and properly executed passive stretching exercise improves the results with time whereas benefits of single steroid injection diminish with time. Hence for the long term (6 months) benefits passive stretching exercise is definitely better than steroid injection.

\section{Comparison of Study with Others}

Celik et al ${ }^{[23]}$ done a study Joint mobilization \& Stretching was applied 3 times per week for 3 weeks for a total of 9 visits. The SI group received 1 injection at baseline. The patientse functional scores were assessed using the Foot and Ankle Ability Measure (FAAM), and pain was evaluated using the Visual Analog Scale (VAS). Outcomes of interest were captured at baseline and at 3-week, 6-week, 12-week, and 1-year follow-ups and the results of this study provide evidence that patients with PF exhibit short-term relief with SI followed by an increase in symptoms that equal the final results produced by manual therapy. The manual therapy group experienced a slow but steady decline in symptoms and showed functional improvement at 1-year follow-up. The results of our study showed the similar results suggesting that SI provides remarkable short-term pain relief and functional improvement and passive stretching is a promising treatment method of achieving longer-term improvements in pain and function compared to steroid injection, as evidenced by the 6 month follow-up data.

Ryan $\mathrm{M}$ et al ${ }^{[24]}$ conducted a study in which The PHYSIO group included 7 physiotherapy-led exercises performed daily over a 12-week period in workers who stand for at least 5 hours a day. The INJECTION group received 1 palpationguided dexamethasone injection followed by a daily routine of calf stretching. Both groups reported significant improvements in FADI and visual analogue scales at 6 and 12 weeks compared with baseline scores. There were no significant changes to plantar fascia thickness reported at the 6- and 12-week follow-up point and they concluded that workers standing for prolonged periods experienced the same short-term therapeutic effectiveness with a physiotherapy led exercise program compared with an injection of corticosteroid with stretching. Compared to aforementioned study, in our study we found that effectiveness of steroid injection was more than stretching exercises up to 12 weeks.

Engkananuwat $\mathrm{P}$ et al ${ }^{[25]}$ conducted a study in which Group 1 was instructed to stretch the Achilles tendon while group 2 simultaneously stretched the Achilles tendon and plantar fascia for 4 weeks. The stretching for both groups was 5 sets of a 20-second stretch and a 20 -second rest. The stretch was performed twice a day for 5 days per week for 4 consecutive weeks. They concluded that patients who reported complete relief from symptoms at the end of the 4-week intervention in the simultaneous stretching group $(\mathrm{n}=14 ; 56 \%)$ were double that of the stretching of the Achilles tendon group $(\mathrm{n}=7$; $28 \%$ ). In comparison with the stretching of the Achilles tendon by itself, the simultaneous stretching of the Achilles tendon and plantar fascia tended to be superior in the pressure 
pain threshold and the clinical success in the participants ${ }^{\text {ee }}$ perspective. Compared to aforementioned study we administered passive stretching therapy for 6 months daily and found the maximum effectiveness of simultaneous stretching exercises at 6 months in terms of the pain relief and functional improvements.

Genc $\mathrm{H}$ et $a l^{[26]}$ conducted a study in which they have given palpation guided $20 \mathrm{mg}$ of methylprednisolone mixed with $0.5 \mathrm{ml}$ of prilocaine at $2 \%$. VAS values in the plantar fasciitis group decreased significantly 1 month after steroid injection and a further decrease was noted 6 months post-injection and incidence of hypoechoic areas decreased significantly at 1 and 6 months post-injection. Thus they concluded that steroid injection could be used in plantar fasciitis treatment for its positive long-term effects. In contrast to this study we found that effectiveness of steroid injection decreased at 6 month compared to 1 month and 3 month follow up.

Crawford $\mathrm{F}$ et al. ${ }^{[27]}$ conducted a study in which patients were allocated randomly, at each episode, to receive either true ultrasound (machine calibrated to deliver a dose of ultrasound

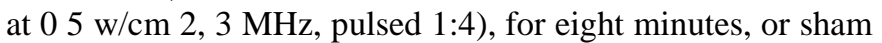
ultrasound (only the timer on the machine activated). Both groups showed a reduction in pain; the improvement was $30 \%$ in the treated group and $25 \%$ in the placebo group (p-0.5 i.e. non-significant). Hence they concluded that therapeutic ultrasound at a dosage of $-5 \mathrm{w} / \mathrm{cm} 2,3 \mathrm{MHz}$, pulsed 1:4, for eight minutes is no more effective than placebo. In contrast to this study, in our study, though the results of therapeutic ultrasound came to be significant at 1 month and 3 month follow up, clinical outcomes (VAS mean 5.27 at 1 month and 5.73 at 3 month) didn't satisfy the expectation of patients. Clinicians offering this treatment should also note that significant pain relief did not continue at the 6 months followup and no considerable effects should be expected after 3 months while prescribing therapeutic ultrasound in plantar fasciitis patients.

The strength of our study is that it was conducted by a single investigator so there were no chances of inter observer variations. As the patients were treated on OPD basis the patients follow up was quite easy. We used both plantar fascia specific and Achilles tendon stretching types of exercises that might have given additional improvements as compared to single type of exercise. As it is proven that plantar fascia specific stretching exercise should be done while keeping the ankle in dorsiflexion to produce more tension in plantar fascia, we employed the same technique. Therapeutic Ultrasound was given in continuous mode which has more beneficial effects than pulsatile mode.

One of the limitations of our study is short duration of follow up. The patients could have been followed up for longer duration to evaluate the long term benefits. Lack of blinding could have resulted in researcher bias. If another investigator would have recorded the outcome, it may have resulted in more reliable readings. We have not used the newer modality Intense Therapeutic Ultrasound (ITU) in which large doses at higher frequency are rates administered. It would have been more helpful to recommend that therapeutic ultrasound group perform calf stretching exercises additionally to enhance the pain relief.

Depending upon the observations, it is obvious that steroid injections provide best results in short term and passive stretching exercises in long term. Hence single shot of corticosteroid injection followed by passive stretching exercises can give instant and long lasting outcomes. Perhaps this can be the subject of a future study.

\section{Conclusion}

From our study, it is concluded that in patients with plantar fasciitis for the short term (up to 3 months) relief of pain and functional improvement, all the three treatment modalities were effective in the order: corticosteroid injection > passive stretching $>$ therapeutic ultrasound. But for the long term improvements (6 months), passive stretching was more effective than corticosteroid injection and therapeutic ultrasound was not effective. Hence out of all the three modalities of treatment, passive stretching exercise is recommended as a primary line of treatment as it is a noninvasive modality, avoids complications associated with steroid injection and has long lasting effects.

\section{References}

1. Cutts S, Obi N, Pasapula C, Chan W. Plantar fasciitis. Ann R Coll Surg Eng. 2012; 94(8):539-42.

2. Riddle DL, Pulisic M, Pidcoe P, Johnson RE. Risk factors for plantar fasciitis: A matched case-control study. J Bone Joint Surg Am. 2003; 85-A:872-7.

3. Kitaoka HB, Luo ZP, Growney ES, Berglund LJ, An KN. Material properties of the plantar aponeurosis. Foot Ankle Int; 1994:15(10):557-60.

4. Lemont H, Ammirati KM, Usen N. Plantar fasciitis. A degenerative process (fasciosis) without inflammation. J Am Podiatr Med Assoc. 2003; 93(3):234-7.

5. Tu P, Bytomski JR. Diagnosis of heel pain. Am Fam physician. 2011; 84(8):909-16.

6. American College of Foot and Ankle Surgeons. The diagnosis and treatment of heel pain. J Foot Ankle Surg. 2001; 40:329-40.

7. Young B, Walker M, Strunce J, Boyles R. A combined treatment approach emphasizing impairment- based manual physical therapy for plantar heel pain: a case series. J Orthop Sports Phys Ther. 2004; 34(11):725-33.

8. Brent Brotzman S, MD Kevin E, Wilk PT. Text Book of Clinical Orthopaedic Rehabilitation; ${ }^{\text {nd }}$ Ed. New York: Churchill living stone, 2001.

9. Singh D, Angel J, Bentley G, Trevino SG. Fortnightly review. Plantar fasciitis. BMJ 1997; 315(7101):172-5.

10. Ram CS. "Taping Techniques" theory and practical application of adhesive tape, edi-1,Jeepee publishers, page-1

11. González-Iglesias J, Fernández-De-Las-Peñas C, Cleland JA, Huijbregts P, Del Rosario Gutiérrez-Vega M. Shortterm effects of cervical kinesio taping on pain and cervical range of motion in patients with acute whiplash injury: a randomized clinical trial. J Orthop Sports Phys Ther. 2009; 39(7):515-21.

12. Genova JM, Gross MT. Effect of foot orthotics on calcaneal eversion during standing and treadmill walking for subjects with abnormal pronation. J Orthop Sports Phys Ther. 2000; 30(11):664-75.

13. Crawford F, Atkins D, Young P, Edwards J. Steroid injection for heel pain: evidence of short-term effectiveness. A randomized controlled trial. Rheumatology (Oxford). 1999; 38(10):974-7.

14. Acevedo JI, Beskin JL. Complications of plantar fascia rupture associated with corticosteroid injection. Foot Ankle Int. 1998; 19(2):91-7.

15. Kennedy JC, Willis RB. The effects of local steroid injections on tendons: a biomechanical and microscopic correlative study. Am J Sports Med. 1976; 4(1):11-21.

16. Draper DO, Castel JC, Castle D: Rate of temperature increase in human muscle during $1 \mathrm{MHz}$ and $3 \mathrm{MHz}$ 
continuous ultrasound. J Orthop Sports Phys Ther. 1995; 22:142-50.

17. DI Giovanni BF, Nawoczenski DA, Lintal ME, Moore EA, Murray JC, Wilding GE et al. Tissue-specific plantar fascia stretching exercise enhances outcomes in patients with chronic heel pain: a prospective, randomized study. J Bone Joint Surg Am. 2003; 85A(7):1270-7.

18. Kane D, Greaney T, Bresnihan B, Gibney R, FitzGerald O. Ultrasound guided injection of recalcitrant plantar fasciitis. Ann Rheum Dis. 1998; 57(6):383-4.

19. Sellman JR. Plantar fascia rupture associated with corticosteroid injection. Foot Ankle Int. 1994; 15(7):37681 .

20. Zanon RG, Kundrat A, Imamura M. Continuous ultrasound for chronic plantar fasclitis treatment. Acta ortop. Bras. 2006; 14:137-40.

21. Farrar JT, Young JP JR, La Moreaux L, Werth JL, Poole RM. Clinical importance of changes in chronic pain intensity measured on an 11-point numerical pain rating scale. Pain. 2001; 94(2):149-58.

22. Martin RL, Irrgang JJ, Burdett RG, Conti SF, Van Swearingen JM. Evidence of validity for the Foot and Ankle Ability Measure (FAAM). Foot Ankle Int. 2005; 26(11):968-83.

23. Celik D, Kuş G, Surma SÖ. Joint Mobilization and Stretching Exercise vs Steroid Injection in the Treatment of Plantar Fasciitis: A Randomized Controlled Study. Foot Ankle Int. 2016; 37(2):150-6.

24. Ryan M1, Hartwell J, Fraser S, Newsham-West R, Taunton J. Comparison of a physiotherapy program versus dexamethasone injections for plantar fasciopathy in prolonged standing workers: a randomized clinical trial. Clin J Sport Med. 2014; 24(3):211-7.

25. Engkananuwat $\mathrm{P}$, Kanlayanaphotporn R, Purepong N. Effectiveness of the Simultaneous Stretching of the Achilles tendon and Plantar Fascia in Individuals With Plantar Fasciitis. Foot Ankle Int, 2017. 1:1071100717732762. Doi: 10.1177/1071100717732762.

26. Genc H, Saracoglu M, Nacir B, Erdem HR, Kacar M. Long-term ultrasonographic follow-up of plantar fasciitis patients treated with steroid injection. Joint Bone Spine. 2005; 72(1):61-5.

27. Crawford F, Snaith M. How effective is therapeutic ultrasound in the treatment of heel pain? Ann Rheum Dis. 1996; 55(4):265-7. 